\title{
Lipocalin 2 regulates expression of MHC class I molecules in Mycobacterium tuberculosis-infected dendritic cells via ROS production
}

\author{
Ji-Ae Choi ${ }^{1,2,3}$, Soo-Na Cho ${ }^{1,2}$, Junghwan Lee ${ }^{1,2,3}$, Sang-Hun Son ${ }^{1,2}$, Doan Tam Nguyen ${ }^{1,2}$, Seong-Ahn Lee ${ }^{1,2}$ and \\ Chang-Hwa Song ${ }^{1,2,3^{*}}$
}

\begin{abstract}
Background: Iron has important roles as an essential nutrient for all life forms and as an effector of the host defense mechanism against pathogenic infection. Lipocalin 2 (LCN2), an innate immune protein, plays a crucial role in iron transport and inflammation. In the present study, we examined the role of LCN2 in immune cells during Mycobacterium tuberculosis (Mtb) infection.

Results: We found that infection with Mtb H37Ra induced LCN2 production in bone marrow-derived dendritic cells (BMDCs). Notably, expression of MHC class I molecules was significantly reduced in LCN2 ${ }^{-1-}$ BMDCs during Mtb infection. The reduced expression of $\mathrm{MHC}$ class I molecules was associated with the formation of a peptide loading complex through LCN2-mediated reactive oxygen species production. The reduced expression of MHC class I molecules affected $\mathrm{CD} 8^{+}$T-cell proliferation in $\mathrm{LCN}^{-1-}$ mice infected with $\mathrm{Mtb}$. The difference in the population of $\mathrm{CD} 8^{+}$ effector T cells might affect the survival of intracellular Mtb. We also found a reduction of the inflammation response, including serum inflammatory cytokines and lung inflammation in $\mathrm{LCN}^{-/-}$mice, compared with wild-type mice, during Mtb infection.
\end{abstract}

Conclusions: These data suggest that LCN2-mediated reactive oxygen species affects expression of MHC class I molecules in $\mathrm{BMDCs}$, leading to lower levels of $\mathrm{CD}^{+}$effector T-cell proliferation during mycobacterial infection.

Keywords: Lipocalin 2, Mycobacterium tuberculosis, MHC class I, Reactive oxygen species

\section{Introduction}

Tuberculosis (TB) caused by Mycobacterium tuberculosis (Mtb) has long been one of the greatest causes of death worldwide [1]. The spread of TB has been exacerbated by the emergence of multidrug-resistant TB and extensively drug-resistant TB [1]. Hence, a full understanding of the

\footnotetext{
*Correspondence: songch@cnu.ac.kr

${ }^{1}$ Department of Microbiology, Department of Medical Science, College of Medicine, Chungnam National University, 266 Munhwa-ro, Jung-gu, 35015 Daejeon, South Korea

Full list of author information is available at the end of the article
}

Mtb-host interaction is needed to establish a strategy for the treatment of TB.

Iron is a crucial nutrient for cell metabolism and plays key roles in DNA synthesis and cellular respiration, which are both important for cell growth and proliferation [2]. Iron is also essential for many pathogenic bacteria, which take up iron via the production of siderophores [3]. During infection, pathogenic bacteria compete with the host for iron acquisition [4]. Administration of iron into culture media has been shown to enhance the growth of Mtb in human macrophages [5]. An Mtb mutant lacking original author(s) and the source, provide a link to the Creative Commons licence, and indicate if changes were made. The images or other third party material in this article are included in the article's Creative Commons licence, unless indicated otherwise in a credit line to the material. If material is not included in the article's Creative Commons licence and your intended use is not permitted by statutory regulation or exceeds the permitted use, you will need to obtain permission directly from the copyright holder. To view a copy of this licence, visit http://creativecommons.org/licenses/by/4.0/. The Creative Commons Public Domain Dedication waiver (http://creativeco mmons.org/publicdomain/zero/1.0/) applies to the data made available in this article, unless otherwise stated in a credit line to the data. 
the mbtB gene, which encodes an enzyme in the biosynthetic pathway of the siderophore mycobactin, exhibits a significantly slower growth rate compared to wild-type (WT) Mtb in human THP-1 macrophages [6]. In addition, excess amounts of iron enhance Mtb growth in the lungs and spleen of BALB/C mice [7]. Thus, the regulation of iron availability is important in the pathogenesis of TB.

Lipocalin 2 (LCN2), a member of the lipocalin protein family, is a transporter of small molecules such as steroids, lipopolysaccharides, iron, and fatty acids in the circulation [8]. LCN2 binds to microbial siderophores such as mycobactin, carboxymycobactin, bacillibactin, and enterobactin [9-11]. The expression of LCN2 in alveolar macrophages and alveolar epithelia is crucial for controlling intracellular Mtb growth $[12,13]$. LCN2 promotes neutrophil recruitment via regulation of chemokine production in macrophages during Mtb infection [14]. In addition, LCN2-deficient neutrophils exhibit impaired ability to phagocytose intra- and extracellular bacteria (Listeria monocytogenes, Candida albicans, and Staphylococcus aureus) [15].

Mtb is able to escape from the phagosome to the cytosol by disrupting the phagosomal membrane [16]. Previous reports suggest that the regulation of major histocompatibility complex (MHC) class I-mediated antigen presentation is important for controlling intracellular Mtb growth [17, 18]. Endogenous peptides are loaded onto MHC class I molecules via peptide loading complex (PLC) components such as calreticulin (CRT), ERp57, tapasin, and protein disulfide isomerase (PDI), which stabilize the conformation of MHC class I molecules $[19,20]$. Endoplasmic reticulum aminopeptidase (ERAP) associated with antigen processing trims the peptides before they are loaded onto MHC class I molecules [21, 22]. Antigen loading onto MHC class I molecules can be regulated by PLC components; however, little is known regarding the precise role of PLC in Mtb infection.

Alveolar macrophages and dendritic cells (DCs) are major immune cell types involved in the initial phagocytic process activated in response to Mtb infection [23]. DCs are important because they act as a bridge between innate and adaptive immunity in Mtb infection [23]. Because antigen presentation through MHC class I molecules is important for $\mathrm{CD}^{+} \mathrm{T}$-cell activation, we investigated the role of LCN2 in the function of MHC class I-mediated $\mathrm{CD}^{+}{ }^{+} \mathrm{T}$ cells. $\mathrm{CD}^{+} \mathrm{T}$ cells perform cytolytic functions to kill Mtb-infected cells via perforin, granzymes, and granulysin or apoptosis; they also produce critical cytokines such as interleukin (IL)-2, interferon (IFN)- $\gamma$, and tumor necrosis factor (TNF)- $\alpha$, which act in response to Mtb infection [24]. However, the function of LCN2 in DCs during Mtb infection is unknown.
The present study investigated the role of LCN2 in the regulation of intracellular Mtb growth via bone marrowderived dendritic cell (BMDC) antigen presentation.

\section{Results \\ Mtb-induced LCN2 is associated with expression of MHC class I molecules in BMDCs}

To determine whether Mtb infection induces LCN2 expression in DCs, we measured the induction of LCN2 in Mtb-infected BMDCs. As shown in Fig. 1A, LCN2 mRNA levels in BMDCs increased in a time-dependent manner in response to Mtb infection. Production of the $\mathrm{LCN} 2$ protein also increased after $24 \mathrm{~h}$ and increased in an MOI-dependent manner in BMDCs infected with Mtb H37Ra (Fig. 1B, C and Additional file 1: Figure S1). Next, we evaluated the expression levels of surface markers (e.g., CD80, CD86, and MHC class I and II molecules) of WT and LCN2 $2^{-I-}$ BMDCs infected with Mtb for $48 \mathrm{~h}$ (Fig. 1D-G). The expression levels of MHC class I molecules were significantly reduced in $\mathrm{LCN} 2^{-/-}$ BMDCs, compared to WT BMDCs, during Mtb infection (Fig. 1D). The expression levels of other costimulatory molecules did not significantly differ between WT and LCN2 ${ }^{-/-}$BMDCs (Fig. 1F, G). These findings suggested that LCN2 is involved in the expression of MHC class I molecules in BMDCs during Mtb infection.

LCN2-induced ROS are involved in expression of MHC class I molecules in Mtb-infected BMDCs

LCN2 is associated with iron homeostasis and intracellular iron levels are related to ROS production [25, 26]. We monitored whether LCN2 affects the induction of intracellular ROS during Mtb infection. The level of Mtbinduced intracellular ROS was significantly elevated in WT BMDCs, compared to LCN2 $2^{-1-}$ BMDCs (Fig. 2A). Similarly, LPS-induced ROS production was significantly reduced in $\mathrm{LCN} 2^{-/-}$BMDCs (Fig. 2B). The levels of PDI, ERO1 $\alpha$, and p47phox, which are responsible for the generation of ROS, were also elevated in WT BMDCs, compared to $\mathrm{LCN} 2^{-1-}$ BMDCs, after Mtb infection (Fig. $2 \mathrm{C}$ and Additional file 1: Figure S2A). Additionally, the levels of antioxidant proteins (e.g., NRF2 and HO-1) were lower in $\mathrm{LCN}^{-1-}$ BMDCs than in WT BMDCs after Mtb infection (Fig. 2D and Additional file 1: Figure S2B). Next, we examined whether intracellular ROS were involved in the expression of MHC class I molecules in BMDCs during Mtb infection. As expected, Mtb-induced expression of MHC class I molecules was significantly reduced by treatment with $0.5 \mathrm{mM} \mathrm{N}$-acetyl cysteine (NAC; ROS scavenger) or $0.5 \mu \mathrm{M}$ diphenyleneiodonium (DPI; NOX inhibitor) at $48 \mathrm{~h}$ in both WT and $\mathrm{LCN} 2^{-/-}$ BMDCs (Fig. 2E). 
A

$\mathrm{Ra}$

\begin{tabular}{|c|c|c|c|c|c|c|c|}
\hline Time(h) & UN & 0.5 & 1 & 3 & 6 & 18 & 24 \\
\hline LCN2 & 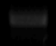 & 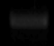 & $=$ & - & $=$ & $=$ & 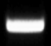 \\
\hline
\end{tabular}

B

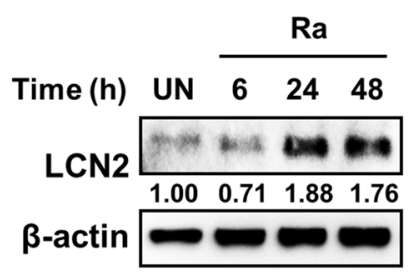

D

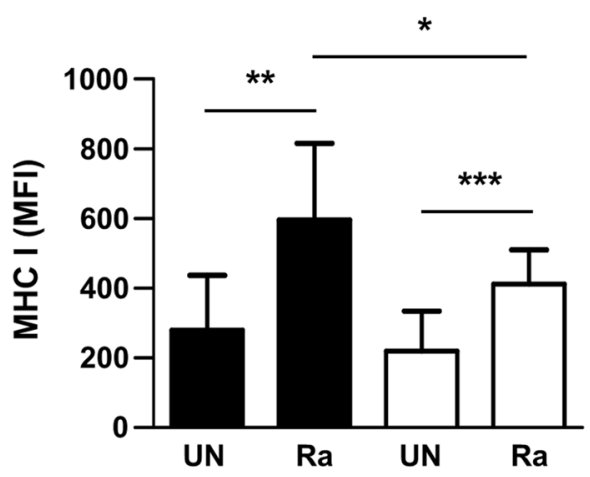

E

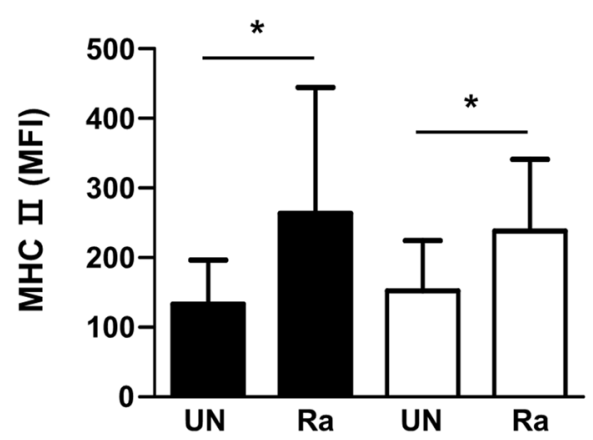

C

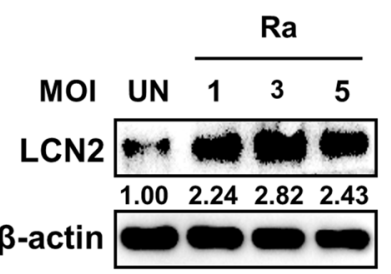

$\mathbf{F}$

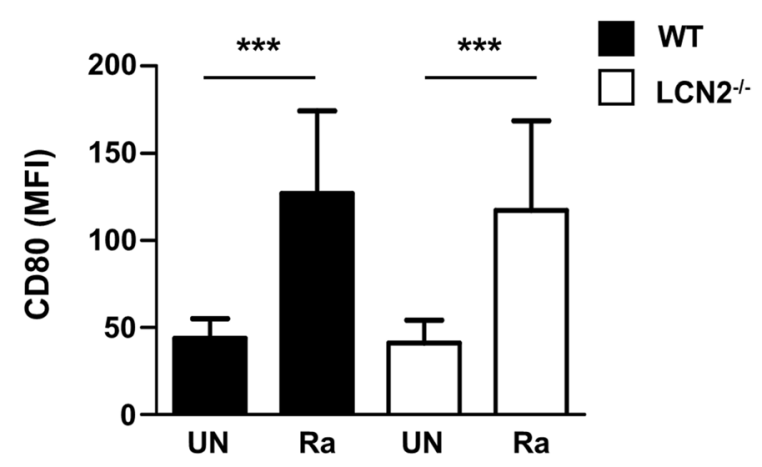

G

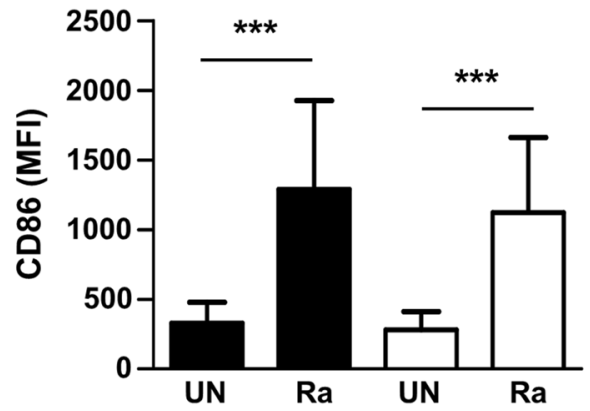

Fig. 1 Mtb-induced LCN2 is associated with MHC class I molecule expression in BMDCs. A, B BMDCs derived from WT mice were infected with Mtb at an $\mathrm{MOI}$ of 1 for the indicated time periods. BMDCs were screened for the induction of LCN2 mRNA and protein during Mtb infection. C BMDCs derived from WT mice were infected with Mtb at a range MOI of 1 to 5 for $48 \mathrm{~h}$ and then screed for LCN2 protein. Western blot bands corresponding to each protein were quantified, and the intensity of each target protein was normalized to the intensity of the $\beta$-actin loading control. The normalized ratio of the unstimulated control (UN) was set as 1.0 to compare target protein abundance in different samples. The normalized ratio is shown at the bottom of the blots. A representative blot from three independent experiments is shown. D-G BMDCs derived from WT and $\mathrm{LCN}^{-/-}$mice were infected with Mtb at an MOI of 1 for $48 \mathrm{~h}$. Expression levels of CD80, CD86, and MHC classes I and II molecules were analyzed on $\mathrm{CD} 11 \mathrm{C}^{+}$-gated BMDCs by flow cytometry using specific antibodies. Data are shown as mean $\pm S D(n=12)$. Statistically significant differences are determined by Mann-Whitney test (non-parametric unpaired two-tailed t-test). ${ }^{*} p<0.05$, ${ }^{* *} p<0.01$, and ${ }^{* * *} p<0.001$ 
Next, we hypothesized that LCN2-mediated ROS played a role in MHC class I antigen presentation through PLC. To confirm this hypothesis, we investigated the expression levels of PLC-related molecules in Mtbinfected BMDCs. As shown in Fig. 3A, the levels of PLCrelated proteins (CRT, ERp57, calnexin, and ERAP1) were reduced in Mtb-infected $\mathrm{LCN}^{-1-}$ BMDCs, compared to WT BMDCs. The levels of PLC-related proteins were suppressed in WT BMDCs pretreated with NAC. Specifically, the levels of ERp57, ERAP1 and CRT were markedly reduced in NAC-treated WT BMDCs (Fig. 3B). The expression of PLC-related protein was also decreased in LCN2 ${ }^{-/-}$BMDCs pretreated with NAC (Fig. 3B).

We examined the levels of ERp57, ERAP1, CRT, calnexin, and MHC class I molecules in $\mathrm{LCN}^{-1-}$ BMDCs after the addition of recombinant LCN2 protein (rLCN2). Notably, the addition of rLCN2 recovered the reduced levels of PLC-related proteins in LCN2-deficient BMDCs (Fig. 3C). The production of PLC-related molecules increased slightly in WT BMDCs following the addition of $1 \mu \mathrm{g} / \mathrm{mL}$ rLCN2 (Fig. 3C). Expression of MHC class I molecules in $\mathrm{LCN}^{-1-}$ BMDCs was significantly enhanced following the addition of $5 \mu \mathrm{g} / \mathrm{mL} \mathrm{rLCN} 2$. Similarly, MHC I expression in WT BMDCs was significantly increased by adding $1 \mu \mathrm{g} / \mathrm{mL}$ rLCN2 (Fig. 3D). Interestingly, intracellular ROS levels in both WT and $\mathrm{LCN} 2^{-1-}$ BMDCs were dose-dependently increased by rLCN2 supplementation at $48 \mathrm{~h}$ after Mtb infection (Fig. 3E). Our findings suggest that LCN2-mediated ROS induce expression of MHC class I molecules in BMDCs through the formation of PLC during Mtb infection.

\section{LCN2-mediated expression of MHC class I molecules affects the generation of effector $\mathrm{CDB}^{+} \mathrm{T}$ cells during $\mathrm{Mtb}$ infection}

To investigate the role of LCN2 in the activation of DCs during Mtb infection, we examined the expression levels of MHC class I, MHC class II, and costimulatory molecules in $\mathrm{CD}_{11 \mathrm{c}^{+}}$cell populations from the mediastinal lymph nodes and lungs of WT and $\mathrm{LCN} 2^{-/-}$mice after intratracheal infection with Mtb for 10 days. Among the BMDC surface markers, only expression of MHC class I molecules was significantly reduced in the mediastinal lymph nodes $(p<0.0001)$ and lung $(p=0.047)$ of $\mathrm{LCN}^{-1-}$ mice, compared to WT mice (Fig. 4A). The expression levels of CD86 and MHC class II molecules were slightly elevated in the mediastinal lymph nodes and lungs of $\mathrm{LCN}^{-1-}$ mice, compared to WT mice (Fig. 4B, D). The expression levels of CD80 were not different in the mediastinal lymph nodes and lungs of between WT and LCN2 $2^{-1-}$ mice (Fig. 4C). Similarly, expression of MHC class I molecules was significantly reduced, but the expression level of CD80 was enhanced in the inguinal lymph nodes of $\mathrm{LCN}^{-/-}$mice after intravenous infection with Mtb for 30 days (Additional file 1: Figure S4A).

To compare the effector T-cell populations in WT and $\mathrm{LCN} 2^{-1-}$ mice, the mice were intratracheally infected with Mtb for 10 days (Fig. 4E, F). The effector CD8 ${ }^{+}$ T-cell population was significantly smaller in the mediastinal lymph nodes $(p=0.0002)$ and lungs $(p=0.028)$ of the $\mathrm{LCN} 2^{-1-}$ mice, compared to WT mice. The effector $\mathrm{CD}_{4}^{+} \mathrm{T}$-cell population was slightly reduced in the mediastinal lymph nodes $(p=0.089)$ and lungs $(p=0.311)$ of the $\mathrm{LCN} 2^{-l-}$ mice, compared to WT mice. However, the effector $\mathrm{CD} 4^{+} \mathrm{T}$-cell population did not significantly differ between WT and $\mathrm{LCN} 2^{-/-}$mice. The effector $\mathrm{CD}^{+}$ T-cell population was significantly reduced in inguinal lymph nodes $(p=0.03)$ and spleen $(p=0.03)$ of the $\mathrm{LCN} 2^{-1-}$ mice, compared to WT mice (Additional file 1: Figure S4B, C).

Next, we examined whether the reduced levels of total T-cells in $\mathrm{LCN}^{-I-}$ mice affected the reduced effector $\mathrm{CD}^{+}$T-cell population during Mtb infection. The $\mathrm{CD}^{+} \mathrm{T}$-cell population was slightly enhanced in the

\footnotetext{
(See figure on next page.)

Fig. 2 LCN2-mediated ROS production is involved in MHC class I molecule expression during Mtb infection. A BMDCs derived from WT and $\mathrm{LCN} 2^{-1-}$ mice were infected with Mtb at an MOI of 1 for the indicated time periods, then stained using ROS-ID Total ROS detection $\mathrm{kit}\left(1 \mu \mathrm{M}, 37^{\circ} \mathrm{C}\right.$, $30 \mathrm{~min})$. Data are shown as mean $\pm \mathrm{SD}(\mathrm{n}=12)$. B BMDCs derived from WT and LCN2 ${ }^{-1}$ - mice were stimulated with LPS (100 ng/ml) for $24 \mathrm{~h}$, then stained using ROS-ID Total ROS detection kit $\left(1 \mu \mathrm{M}, 37^{\circ} \mathrm{C}, 30 \mathrm{~min}\right)$. Data are shown as mean $\pm S D(n=5)$. Intracellular ROS level was detected by flow cytometry in CD11 $\mathrm{c}^{+}$-gated BMDCs. C, D BMDCs derived from WT and LCN2 ${ }^{-1}$ mice were infected with Mtb at an MOI of 1 for the indicated time periods. Western blotting was performed using antibodies against PDI, ERO1 a, p47phox, NRF2 and HO-1. LPS (1 $\mu \mathrm{g} / \mathrm{ml}, 1 \mathrm{~h})$ were used as positive controls. Western blot bands corresponding to each protein were quantified, and the intensity of each target protein was normalized to the intensity of the $\beta$-actin loading control. The normalized ratio of the WT unstimulated control (UN) was set as 1.0 to compare target protein abundance in different samples. The normalized ratio is shown at the bottom of the blots. A representative blot from three independent experiments is shown. E BMDCs derived from WT and LCN2 ${ }^{-/-}$mice were preincubated with NAC (0.2 or $\left.0.5 \mathrm{mM}\right)$ or DPI $(0.5 \mu \mathrm{M})$ for $30 \mathrm{~min}$, then infected with Mtb at an MOI of 1 for $48 \mathrm{~h}$. The expression of MHC class I molecules was analyzed by flow cytometry on CD11 $\mathrm{c}^{+}$-gated BMDCs. Data are shown as mean $\pm S D(n=6)$. Statistically significant differences were determined by Mann-Whitney test (non-parametric unpaired two-tailed t-test; ${ }^{*}$ ) or Wilcoxon signed-rank test (non-parametric paired two-tailed t-test; ${ }^{*}$ ). ${ }^{*} p<0.05,{ }^{* *} p<0.01$, and ${ }^{* *} p<0.001 ;{ }^{\#} p<0.05,{ }^{\# \#} p<0.01$, and $\#$ \#\#\# 0.001
} 
A

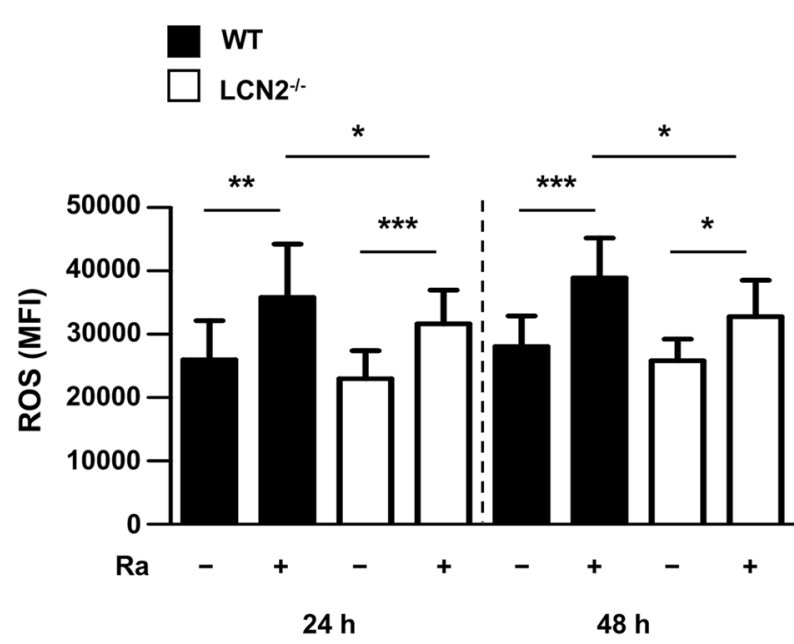

C

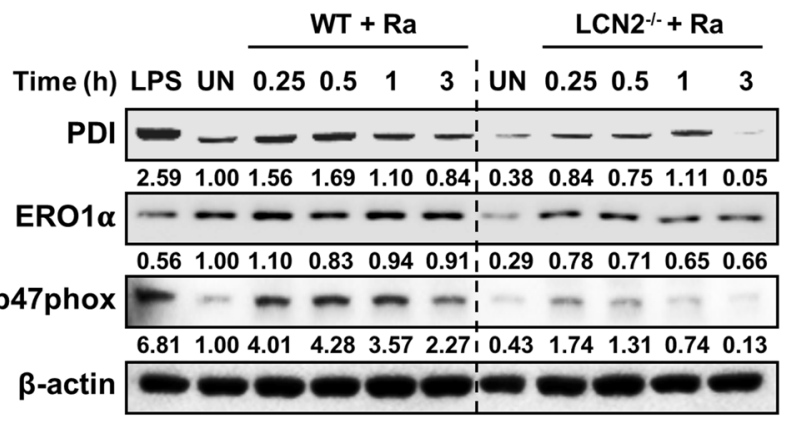

E

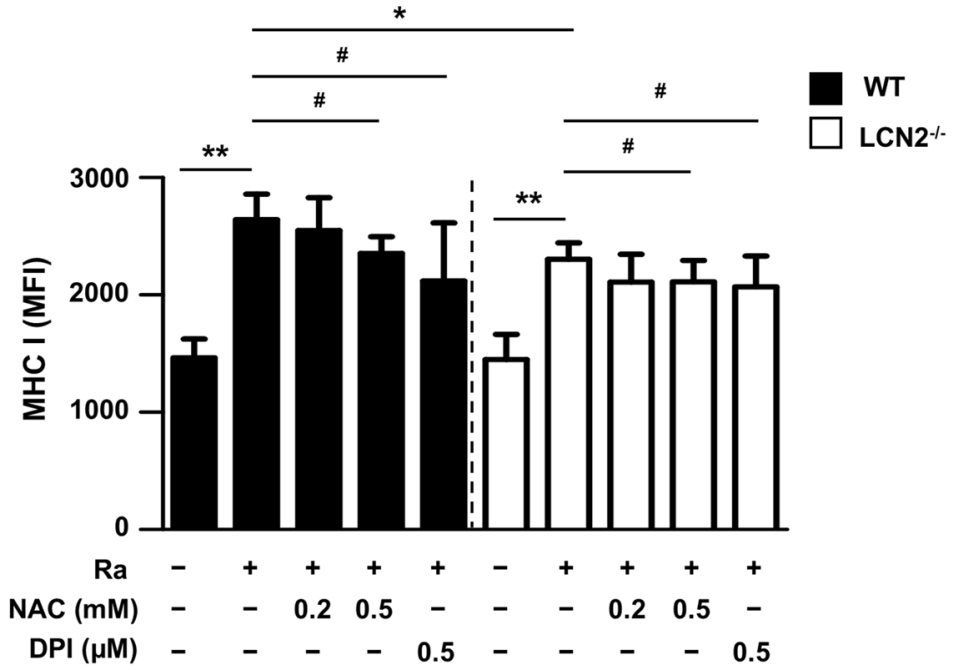

Fig. 2 (See legend on previous page.)

B
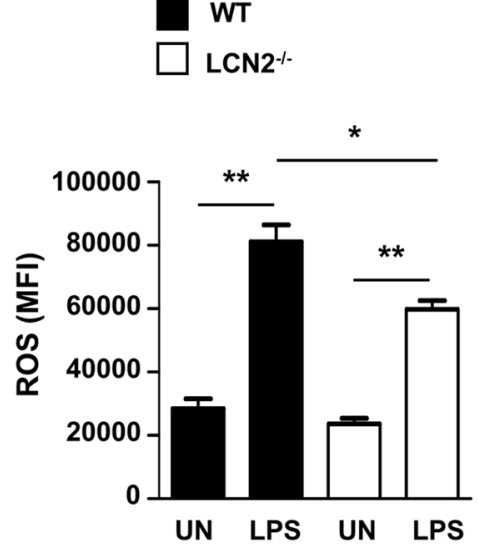

D

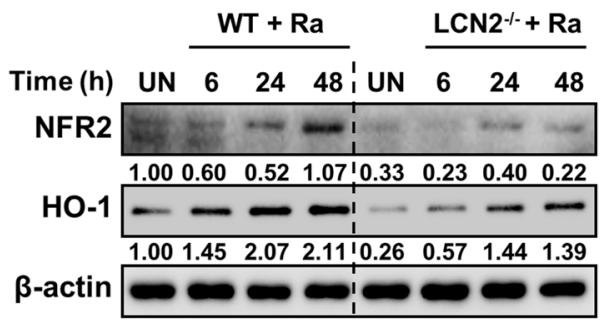


mediastinal and inguinal lymph nodes of $\mathrm{LCN}^{-1-}$ mice, compared to WT mice. However, the $\mathrm{CD}^{+}, \mathrm{CD}^{+}$, and $\mathrm{CD}^{+}{ }^{+}$-cell populations did not significantly differ between the WT and $\mathrm{LCN}^{-/-}$mice (Additional file 1: Figure S5). In addition, rLCN2 compensation significantly increased the effector $\mathrm{CD}^{+} \mathrm{T}$-cell population when $\mathrm{CD}^{+}$naïve $\mathrm{T}$ cells were co-cultured with $\mathrm{LCN} 2^{-1-}$ BMDCs infected with Mtb (Additional file 1: Figure S6). Taken together, these results suggest that LCN2 affects the generation of effector $\mathrm{CD} 8^{+} \mathrm{T}$ cells by regulating the expression of MHC class I molecules in DCs during Mtb infection.

To confirm whether Mtb primed-CD8 ${ }^{+}$T-cells suppressed intracellular Mtb growth, $\mathrm{CD} 8^{+} \mathrm{T}$ - cells were isolated from the spleen of mice that had been infected with Mtb for 10 days; the cells were then co-cultured with Mtb-infected WT BMDMs. As expected, Mtb-primed $\mathrm{CD}^{+}{ }^{-}$T-cells of WT and $\mathrm{LCN} 2^{-l-}$ mice significantly suppressed the intracellular survival of Mtb, compared to the uninfected control. Notably, CD8 ${ }^{+}$T-cells from WT mice more effectively suppressed Mtb growth, compared to $\mathrm{CD}^{+} \mathrm{T}$ cells from $\mathrm{LCN} 2^{-/-}$mice (Additional file 1 : Figure S7).

\section{LCN2 regulates intracellular Mtb survival}

Because inflammation plays a role in the regulation of Mtb growth [27], we measured the inflammation level in an in vivo system during Mtb infection. WT and $\mathrm{LCN} 2^{-1-}$ mice were intratracheally infected with Mtb for 10 days, after which the histological aspects of the lungs were monitored. The data showed that inflammatory cells were slightly enhanced in the lung tissues of WT mice, compared to the $\mathrm{LCN} 2^{-1-}$ mice (Fig. $5 \mathrm{~A}$ and Additional file 1: Figure S8A). Inflammatory cytokines such as IL-6, TNF- $\alpha$, and MCP- 1 were significantly reduced in the sera of LCN2 ${ }^{-/-}$mice, compared to WT mice (Fig. 5B). Similarly, levels of IL- 6 and MCP-1 were significantly lower in the lung homogenates of $\mathrm{LCN} 2^{-/-}$mice compared to in WT mice (Additional file 1: Figure S8B). These results suggested that LCN2 is closely associated with inflammation in Mtb-infected mice.

To establish the effect of LCN2 on the regulation of intracellular survival of Mtb in an in vivo system, we measured intracellular Mtb by CFU counts in the lungs at 10 days post-infection. Mtb survival was significantly enhanced in the lungs of $\mathrm{LCN} 2^{-/-}$mice, compared to WT mice $(p=0.003)$ (Fig. 5C). Similarly, intracellular Mtb was significantly enhanced in the spleen of $\mathrm{LCN} 2^{-/-}$ mice at 30 days post-infection, compared to WT mice $(p=0.0001)$ (Additional file 1: Figure S9).

Our findings suggested that Mtb-induced LCN2 is important for the generation of $\mathrm{CD}^{+}$effector $\mathrm{T}$ cells in response to mycobacterial infection because it affects the induction of MHC class I expression in DCs.

\section{Discussion}

LCN2 is known to regulate growth of bacteria (e.g., Escherichia coli and Salmonella typhimurium) through iron depletion [28, 29]. LCN2 has been shown to restrict the growth of Mtb by limiting replication through iron sequestration in macrophages and alveolar epithelial cells $[12,13]$. In the present study, LCN2 in DCs was found to play a critical role in antigen presentation processing during Mtb infection.

Intracellular iron is responsible for the generation of ROS and the hydroxyl radical (HO·) via the Fenton reaction [30]. The findings of a recent study suggested that the expression of MHC class I molecules was reduced in an intracellular iron-limiting environment [31]. Here, we showed that the production of PLC components and ROS was reduced in $\mathrm{LCN} 2^{-/-}$BMDCs during Mtb infection. Among the PLC components, the levels of ERAP1 and calnexin were strongly suppressed by treatment with NAC, a ROS scavenger. Calnexin promotes the initial folding of MHC class I heavy chains through direct binding to the disulfide bond prior to dimerization with $\beta 2-\mathrm{m}[32]$. These results suggest that reduction of endoplasmic reticulum (ER) stress might

\footnotetext{
(See figure on next page.)

Fig. 3 Effects of LCN2-mediated ROS on formation of the PLC in BMDCs. A BMDCs derived from WT and LCN2 ${ }^{-/-}$mice were infected with Mtb at an $\mathrm{MOl}$ of 1 for the indicated time periods. B BMDCs derived from WT and LCN2 ${ }^{-/}$mice were preincubated with NAC (0.2 or $\left.0.5 \mathrm{mM}\right)$ for $30 \mathrm{~min}$, then infected with Mtb at an $\mathrm{MOI}$ of 1 for $48 \mathrm{~h}$. Western blotting was performed using antibodies against CRT, ERp57, ERAP1, and calnexin. CE BMDCs derived from WT and LCN2 ${ }^{-/-}$mice were infected with Mtb at an MOl of 1, then incubated with recombinant LCN2 (1 or $\left.5 \mu \mathrm{g} / \mathrm{ml}\right)$ for $48 \mathrm{~h}$. C Western blotting was performed using antibodies against CRT, ERp57, ERAP1, and calnexin. Western blot bands corresponding to each protein were quantified, and the intensity of each target protein was normalized to the intensity of the $\beta$-actin loading control. The normalized ratio of the WT control (WT unstimulated control (UN) or Ra-only infected WT control) was set as 1.0 to compare target protein abundance in different samples. The normalized ratio is shown at the bottom of the blots. A representative blot from three independent experiments is shown. D The expression of MHC class I molecules was analyzed by flow cytometry on CD11 $\mathrm{c}^{+}$-gated BMDCs. Data are shown as mean $\pm \mathrm{SD}(\mathrm{n}=8)$. E Levels of intracellular ROS were determined by flow cytometry using ROS-ID Total ROS detection kit $\left(1 \mu \mathrm{M}, 37^{\circ} \mathrm{C}, 30 \mathrm{~min}\right)$ in $\mathrm{CD} 11 \mathrm{C}^{+}$-gated BMDCs. Data are shown as mean $\pm S D(n=10)$. Statistically significant differences were determined by Mann-Whitney test (non-parametric unpaired two-tailed t-test; ${ }^{*}$ ) or Wilcoxon signed-rank test (non-parametric paired two-tailed t-test; ${ }^{\#)}{ }^{*} p<0.05,{ }^{* *} p<0.01$, and ${ }^{* * *} p<0.001 ;{ }^{\#} p<0.05,{ }^{\# \#} p<0.01$, and ${ }^{\# \# \#} p<0.001$
} 
A

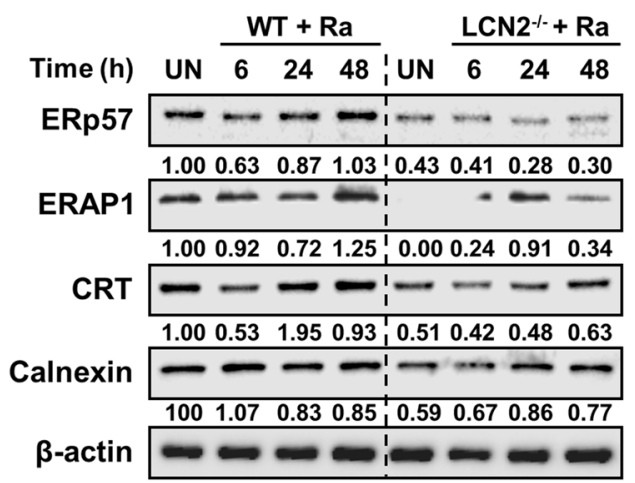

B

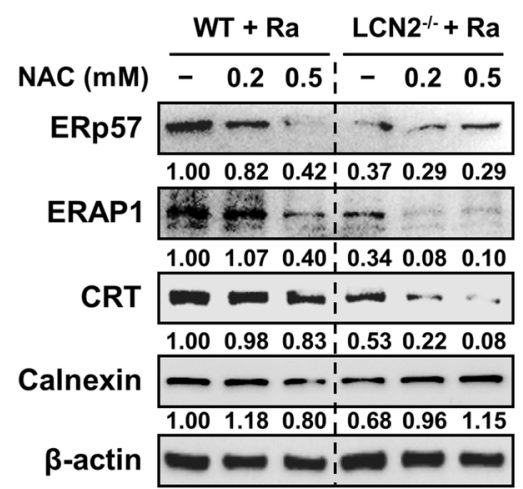

C

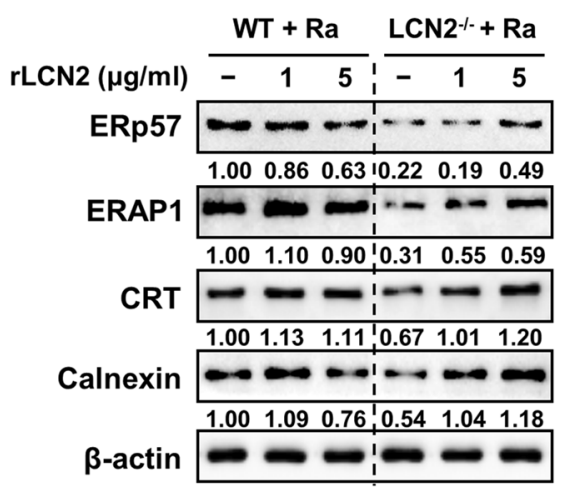

D

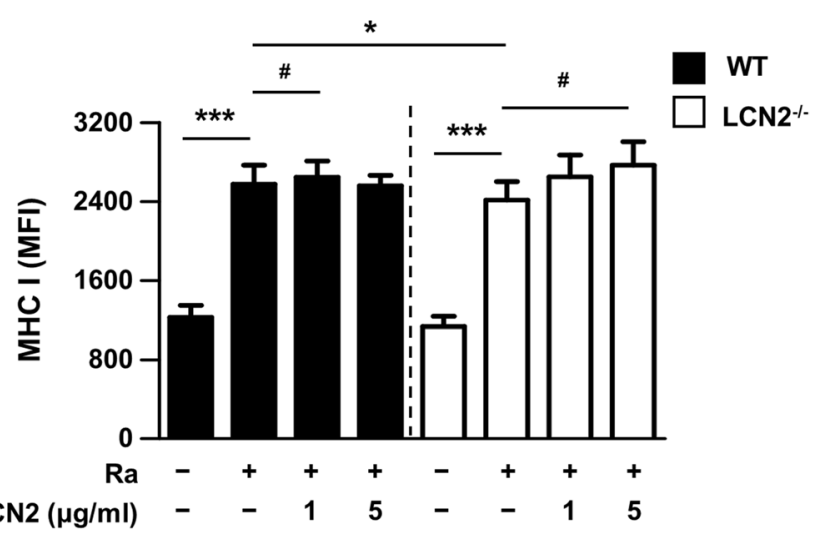

E

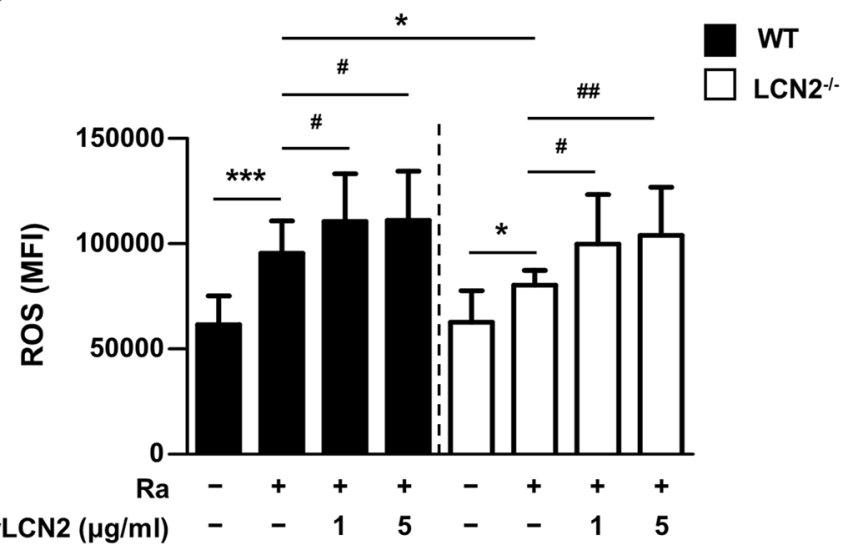

Fig. 3 (See legend on previous page.)

affect PLC formation; ER stress induces CRT/calnexin production and regulates the posttranscriptional level of the ERAP1 gene $[33,34]$. The results of some studies have suggested that optimal assembly of the MHC class I molecule via PLC components is essential in the host defense against Mtb infection [17, 18]. The reduced levels of intracellular iron may have a suppressive effect on PLC formation, potentially leading to the 
A

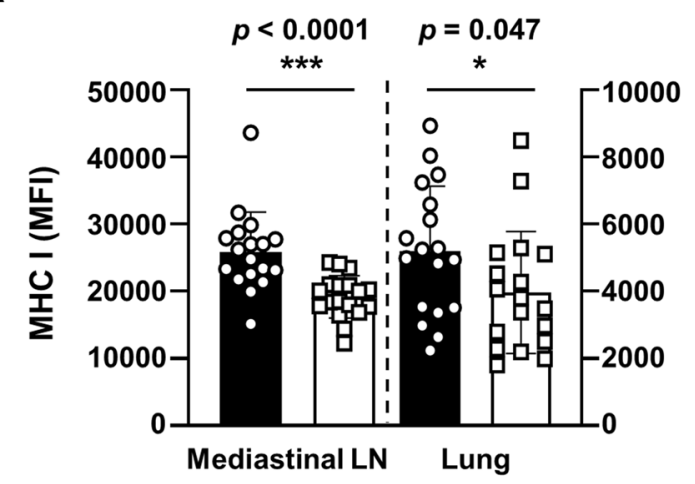

B

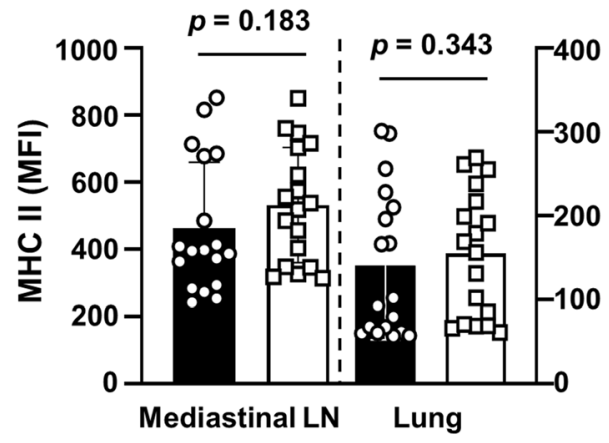

E

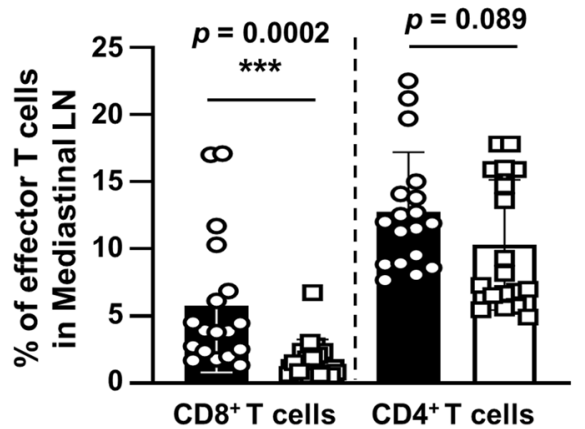

C

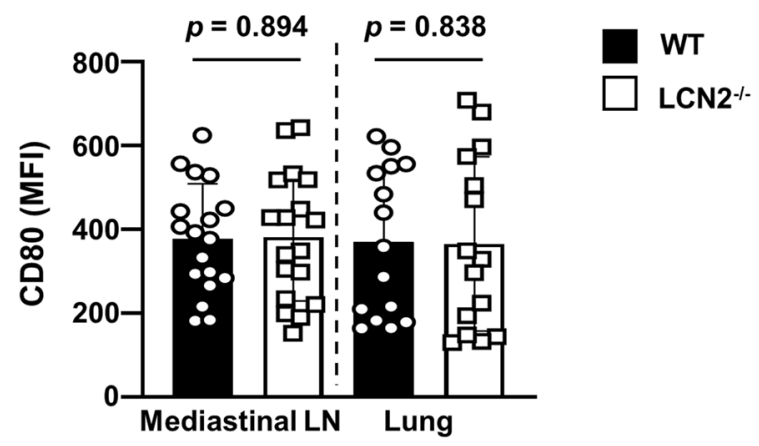

D

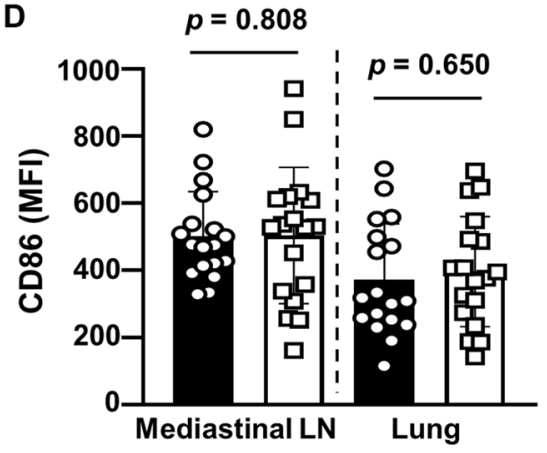

F

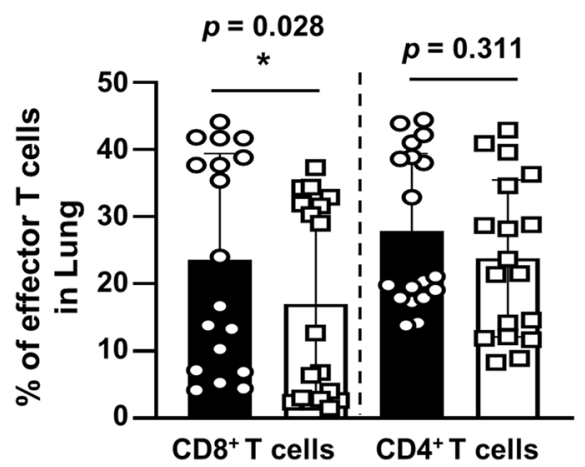

Fig. 4 LCN2 regulates MHC class I molecule expression and CD8 ${ }^{+}$effector T-cell generation following intratracheal Mtb infection. WT and LCN2 ${ }^{-/-}$ mice were intratracheally infected with Mtb $\left(10^{6} \mathrm{CFU}\right)$ for 10 days. A-D Expression levels of CD80, CD86, and MHC classes I and II molecules were analyzed by flow cytometry using specific antibodies in CD11 $C^{+}$cell populations from mediastinal lymph nodes and lungs. Data are shown as mean $\pm \mathrm{SD}\left(\mathrm{n}=18,6\right.$ mice/group) and are pooled from three independent experiments. $\mathbf{E}, \mathbf{F}$ Levels of effector $T$ cells $\left(C D 62 L^{-} \mathrm{CD} 44^{+}\right)$ were detected by flow cytometry in $\mathrm{CD}^{+}$cell populations from mediastinal lymph nodes and lungs. Data are shown as mean $\pm \mathrm{SD}(\mathrm{n}=18,6$ mice/group) and are pooled from three independent experiments. Statistically significant differences were determined by Mann-Whitney test (non-parametric unpaired two-tailed t-test). ${ }^{*} p<0.05$, and ${ }^{* * *} p<0.001 \mathrm{LN}$, lymph node 
downregulation of MHC class I molecule expression in LCN2 ${ }^{-1-}$ BMDCs. Our results suggest that ROS generation by LCN2 is an important factor affecting MHC class I molecule expression via PLC formation during Mtb infection. However, the regulation of MHC class I molecule expression is highly complex and involves multiple factors, and some factors related to MHC class I molecule expression still need to be investigated.

We showed that the levels of MHC class I molecule expression in $\mathrm{CD}_{11 \mathrm{c}^{+}}$cells were lower in the mediastinal lymph nodes of $\mathrm{LCN}^{-1-}$ mice, compared to WT mice, during Mtb infection. The $\mathrm{CD}^{+}$effector T-cell populations were also significantly smaller in the mediastinal lymph nodes and lungs of the $\mathrm{LCN} 2^{-/-}$mice, compared to WT mice. The small population of $\mathrm{CD}^{+}$ effector T-cells in the absence of LCN2 was presumably due to impaired antigen presentation capacity, based on the reduced expression of MHC class I molecules in CD $11 \mathrm{c}^{+}$cells in the mediastinal lymph nodes. Therefore, the reduced population of $\mathrm{CD}^{+}$effector T-cells might contribute to the enhanced intracellular survival of Mtb in the lungs of $\mathrm{LCN} 2^{-l-}$ mice, compared to WT mice.

The levels of proinflammatory cytokines (e.g., TNF- $\alpha$, IL-6, and MCP-1) were reduced in the sera of $\mathrm{LCN} 2^{-1-}$ mice after Mtb infection. Our findings are consistent with the results of other studies, which showed that LCN2 promotes inflammation during mycobacterial infections $[13,14,35]$. MCP-1 contributes to the organization of granulomatous inflammation through recruitment and accumulation of macrophages and $\mathrm{T}$ lymphocytes in the lungs following early Mtb infection [27]. TNF- $\alpha$ enhances the ability of macrophages to phagocytose and kill mycobacteria $[36,37]$. In addition, TNF- $\alpha$ promotes apoptosis of Mtb-infected alveolar macrophages and plays a role in the formation and maintenance of granulomas [38, 39]. IL-6 is critically important for regulating intracellular survival of Mtb [40]. Thus, reduced proinflammatory cytokine production in LCN2 $2^{-/-}$mice might constitute a favorable environment for Mtb survival.

Finally, we observed elevated numbers of intracellular Mtb in the lungs and spleen of $\mathrm{LCN} 2^{-1-}$ mice, compared to WT mice, during Mtb infection. Iron-related immune modulatory mechanisms have been suggested to reduce iron levels and promote the reduction of IFN- $\gamma$ receptors; they may also modulate the expression of MHC class I molecules [31, 41]. Furthermore, LCN2 might affect the polarization of M1 macrophages or their clearance by enhancing the phagocytic/ autophagic process $[42,43]$. The results of our previous study suggested that M1 macrophages were better able to control intracellular Mtb, compared to M2 macrophages [44]. In summary, our findings indicate a new crucial protective role for $\mathrm{LCN} 2$ in $\mathrm{CD}^{+}$effector $\mathrm{T}$-cell activation via regulation of $\mathrm{MHC}$ class I molecule expression in BMDCs, in response to mycobacterial infection. Therefore, regulation of LCN2 production might represent an important therapeutic approach for future treatment of tuberculosis.

\section{Conclusions}

In this study, we found that LCN2-mediated ROS generation affects $\mathrm{MHC}$ class I molecule expression via PLC formation during Mtb infection. LCN2-mediated expression of MHC class I molecules in DCs regulates intracellular mycobacterial growth by affecting the effector $\mathrm{CD}^{+}{ }^{+} \mathrm{T}$-cell population. LCN2 plays a protective role in the suppression of intracellular mycobacteria. An Mtb H37Ra infection model was used, because the gene content and sequence of the Mtb H37Ra genome is highly similar to that of Mtb H37Rv. Taken together, our findings suggest that LCN2 functions as an MHC class 1 modulator during mycobacterial infection.

\section{Materials and methods Cell cultures}

Murine BMDCs were generated, cultured, and purified as previously described [45]. BMDCs were cultured at $37{ }^{\circ} \mathrm{C}$ in the presence of $5 \% \mathrm{CO}_{2}$ in RPMI 1640 media (Welgene Co., Daegu, South Korea) supplemented with 100 unit $/ \mathrm{ml}$ penicillin/streptomycin (Lonza, Walkersville, MD, USA), 10\% fetal bovine serum (Gibco, Waltham, MA, USA), 20 ng/ml GM-CSF (CreaGene; Geyonggi-do, South Korea), and $5 \mathrm{ng} / \mathrm{mL}$ IL-4 (CreaGene) for 7 days. Murine bone marrow-derived macrophages (BMDMs) were isolated from femurs and tibias of C57BL/6 mice (6-9 weeks old) and differentiated by growth for 3-5 days in Dulbecco's modified Eagle medium containing M-CSF $(25 \mathrm{ng} / \mathrm{mL}$; R\&D Systems, Minneapolis, MN, USA).

\footnotetext{
(See figure on next page.)

Fig. 5 LCN2 promotes inflammation following Mtb infection. WT and LCN2 ${ }^{-/-}$mice were intratracheally infected with Mtb (10 ${ }^{6}$ CFU) for 10 days. A Lung inflammation was determined by hematoxylin and eosin staining. Sale bars $=200 \mu \mathrm{m}$. B Levels of inflammatory cytokines in sera were determined using a CBA mouse inflammation kit by flowcytometry. Data are shown as mean \pm SD ( $n=9,3$ mice/group) and are pooled from three independent experiments. C Bacterial loads in the lungs were analyzed by CFU assays on $7 \mathrm{H} 10$ plates. Data are shown as mean \pm SD ( $\mathrm{n}=9,3$ mice/group) and are are pooled from three independent experiments. Statistically significant differences were determined by Mann-Whitney test (non-parametric unpaired two-tailed t-test). ${ }^{*} p<0.05,{ }^{* *} p<0.01$, and ${ }^{* * *} p<0.001$
} 
A

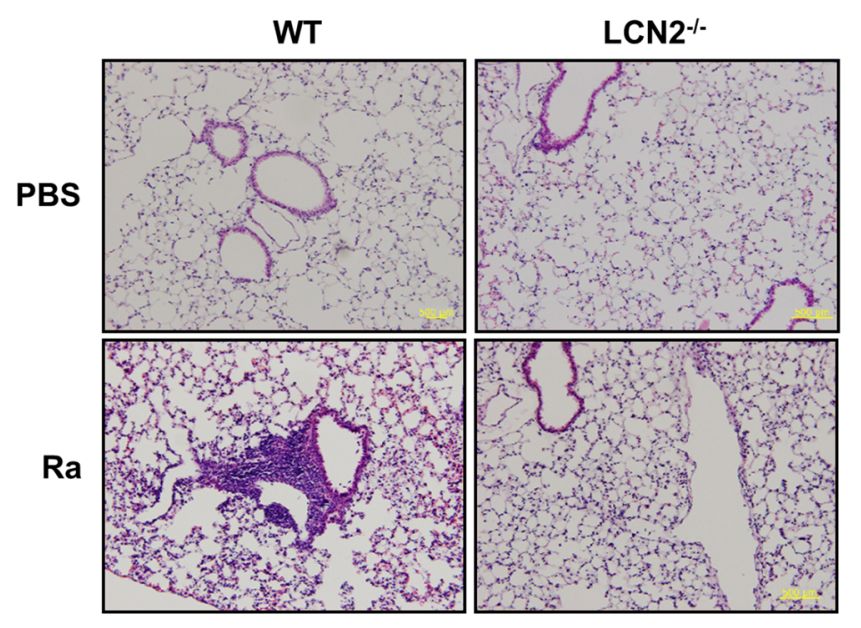

B
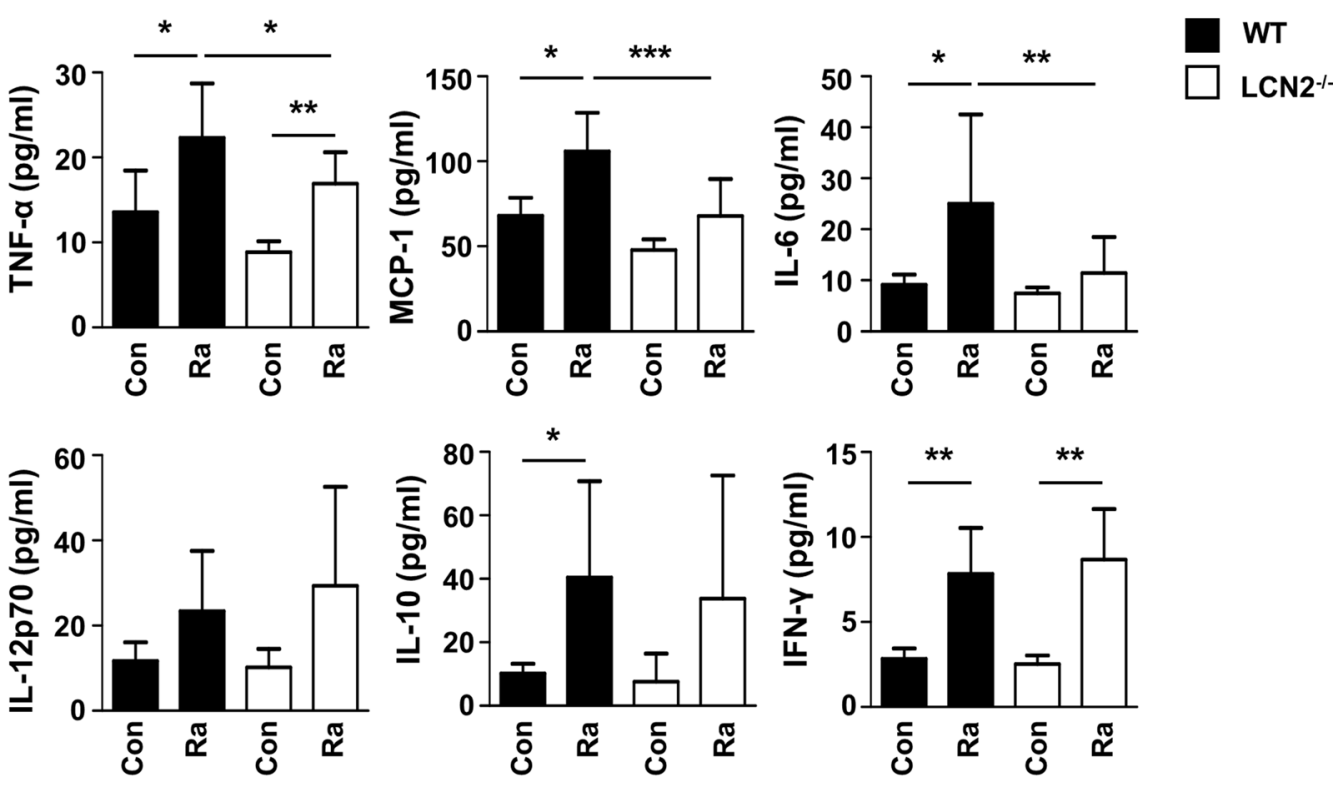

C

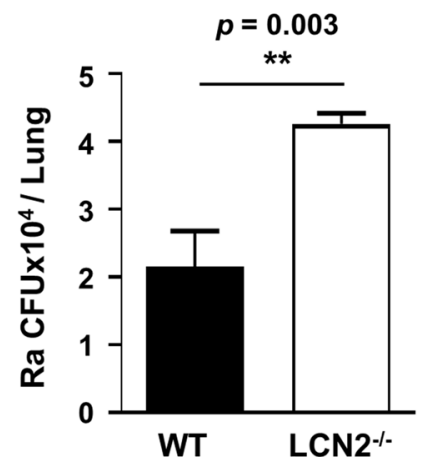

Fig. 5 (See legend on previous page.) 


\section{In vivo model}

C57BL/6 WT and $\mathrm{LCN}^{-/-}$mice (male, $8-9$ weeks of age) were used in this study and housed under specific pathogen-free conditions. WT mice were purchased from Samtako (Geyonggi-do, South Korea). LCN2 ${ }^{-/-}$mice were kindly provided by Dr. Kiyoshi Mori (Kyoto University, Kyoto, Japan) and Dr. Shizuo Akira (Osaka University, Osaka, Japan). Mice were infected intratracheally with Mtb strain H37Ra $\left[10^{6}\right.$ colony-forming units (CFU)] in $50 \mu \mathrm{l}$ phosphate-buffered saline (PBS) for 10 days. Samples from the lungs, mediastinal lymph nodes, lung homogenates and blood sera were collected at 10 days after Mtb infection. Other mice were intravenously infected with Mtb strain H37Ra $\left(10^{6} \mathrm{CFU}\right)$ in $150 \mu \mathrm{l}$ PBS for 30 days. Samples from the inguinal lymph nodes and spleen were collected at 30 days after Mtb infection. These organs were used for histological analysis, detection of cell surface markers, and CFU analysis.

\section{Bacterial culture and CFU assay}

Mtb strain H37Ra (ATCC 25177) was purchased from the American Type Culture Collection and cultured in Middlebrook $7 \mathrm{H} 9$ liquid medium containing $10 \%$ oleic acid, albumin, dextrose, and catalase, combined with 5\% glycerol. Aliquots of the upper bacterial suspension of Mtb H37Ra were frozen at $-80{ }^{\circ} \mathrm{C}$ until use. Cells were infected with Mtb H37Ra at a multiplicity of infection (MOI) of 1 for $3 \mathrm{~h}$. To remove the extracellular mycobacteria, cells were washed with PBS and incubated with fresh medium without antibiotics for an additional period. The cells were lysed in autoclaved distilled water to release intracellular bacteria. The lysates were plated separately on $7 \mathrm{H} 10$ agar plates and incubated at $37^{\circ} \mathrm{C}$ for 21 days.

\section{RNA extraction and reverse transcription-polymerase chain reaction assay}

Total RNA was extracted from Mtb-infected BMDCs using TRIzol reagent (Invitrogen, Carlsbad, CA, USA), in accordance with the manufacturer's instructions; mRNA was reverse transcribed into cDNA using the Reverse Transcription Kit (ELPIS Biotech, Daejeon, South Korea). The cDNA was amplified using specific primers.

\section{Western blotting assay}

Western blotting analysis was performed as described previously [46] using primary antibodies against LCN2 (R\&D Systems), ERp57, ERAP1 (Abcam; Cambridge, MA, USA), ERO1 $\alpha$ (Novus Biologicals; Littleton, CO, USA), HO-1 (Enzo Life Sciences; Farmingdale, NY, USA), CRT, NRF2, calnexin, p47phox, $\beta$-actin (Santa Cruz Biotechnology; Dallas, TX, USA), and PDI (Cell Signaling; Danvers, MA, USA). Goat anti-rabbit-IgG-HRP (Cell
Signaling), donkey anti-goat IgG (Santa Cruz Biotechnology), and rabbit anti-mouse-IgG-HRP (Calbiochem, San Diego, CA, USA) were used as secondary antibodies. The blots were quantified using an Alliance Mini $4 \mathrm{M}$ (UVItec, Cambridge, UK). Western blot bands corresponding to each protein were quantified, and the intensity of each target protein was normalized to the intensity of the $\beta$-actin loading control. The normalized ratio of the control was set as 1.0 to compare target protein abundance in different sample. The normalized ratios of target proteins were used to compare target protein abundance in different samples. The normalized ratio is shown at the bottom of the blots. The normalized intensity values of three different experiments are plotted as mean \pm standard deviation (SD).

\section{Reagents}

Tunicamycin, NAC, and diphenyleneiodonium were purchased from Calbiochem. Lipopolysaccharide (LPS) was purchased from Sigma (St. Louis, MO, USA). These reagents were dissolved in dimethyl sulfoxide (Sigma) or distilled water.

\section{Reactive oxygen species (ROS) analysis}

To measure intracellular ROS levels, cells were stained using ROS-ID Total ROS detection kit (Enzo Life Sciences; Farmingdale, NY, USA) for $30 \mathrm{~min}$ at $37^{\circ} \mathrm{C}$. After they had been washed with PBS, the cells were fixed with $4 \%$ paraformaldehyde (PFA). Samples were analyzed on a FACS Canto II cytometer (BD Biosciences). The data were processed using Flow Jo (Tree Star; Ashland, OR, USA).

\section{BMDC surface marker and effector T-cell analysis}

BMDCs infected with Mtb at an MOI of 1 for $48 \mathrm{~h}$, and total single cells extracted from the organs of WT and $\mathrm{LCN} 2^{-I-}$ mice infected with $\mathrm{Mtb}$, were stained with specific monoclonal antibodies (mAbs) for $20 \mathrm{~min}$ at $4{ }^{\circ} \mathrm{C}$, then washed with PBS. After they had been washed, the cells were fixed with 4\% PFA. To ascertain cell surface marker expression, cells were analyzed using a FACS Canto II cytometer (BD Biosciences). Data analysis was performed using Flow Jo software (Tree Star). For FACS analysis, fluorescein isothiocyanate-conjugated anti-CD80, allophycocyanin (APC)-conjugated antiCD86, phycoerythrin (PE)-Cy7-conjugated anti-CD11c, PE-conjugated anti-MHC class I, Alexa700-conjugated anti-MHC class II, PE-conjugated anti-CD44, and PE-Cy7-conjugated anti-CD62L mAbs were purchased from eBioscience (San Diego, CA, USA). APC-conjugated anti-CD3, APC-Cy7-conjugated anti-CD4, and Alexa700-conjugated anti-CD8 mAbs were obtained from BD Biosciences (San Jose, CA, USA). 
Mouse sera and lung homogenates cytokine analysis

Mouse sera and lung homogenates were collected for cytokine profiling after Mtb infection, then kept frozen until batch analysis. The lung tissues were homogenized at $4{ }^{\circ} \mathrm{C}$. Proinflammatory cytokines [e.g., IL-6, IL-12p70, TNF$\alpha$, IL-10, IFN- $\gamma$, and monocyte chemoattractant protein (MCP)-1] were quantified using a cytometric bead array (CBA) mouse inflammation kit (BD Biosciences) by a FACS Canto II cytometer (BD Biosciences); the data were processed using Flow Jo (Tree Star).

\section{In vitro T-cell cytotoxicity assay}

Responder $\mathrm{CD}^{+} \mathrm{T}$ cells were isolated using a magneticactivated cell sorting system (Miltenyi Biotec, Bergisch Gladbach, Germany) with CD8-coated magnetic microbeads from the spleen of $\mathrm{WT}$ and $\mathrm{LCN} 2^{-1-}$ mice intravenously infected with Mtb for 10 days, in accordance with the manufacturer's instructions. BMDMs $\left(2 \times 10^{5}\right.$ cells/well) were infected with Mtb at an MOI of 1 for $3 \mathrm{~h}$. After $24 \mathrm{~h}$, the BMDMs were cocultured with $\mathrm{CD}^{+}$ $\mathrm{T}$ cells $\left(1 \times 10^{6}\right)$ at a BMDM:T cell ratio of $1: 5$. On day 6 of coculture, the intracellular bacteria were analyzed by CFU assays.

\section{Hematoxylin and eosin staining}

Mouse lung tissues were infected with Mtb for 10 days; they were then collected, fixed in $10 \%$ formalin, and embedded in paraffin. Tissue sections on paraffin-embedded tissue arrays were deparaffinized and rehydrated using a graded alcohol series. The tissue sample slides were incubated with Gill's V Hematoxylin (Muto, Tokyo, Japan) for $5 \mathrm{~min}$, washed under running tap water for $5 \mathrm{~min}$, decolorized with $0.3 \% \mathrm{HCl}$ solution for $15 \mathrm{~s}$, and rinsed with Scott's Bluing solution for $7 \mathrm{~min}$. The cytoplasm was stained with Eosin Y solution for 2 min; the slides were then dehydrated, cleared, and mounted. The stained samples were analyzed with an Axiophot microscope (Carl Zeiss, Jena, Germany).

\section{Statistical analysis}

For statistical analyses, data obtained from independent experiments are presented as means \pm SD. All experiments were performed independently and repeated at least three times. Statistically significant differences between the two groups were determined by MannWhitney test (non-parametric unpaired two-tailed t-test) or Wilcoxon signed-rank test (non-parametric paired two-tailed t-test) using GraphPad Prism Software (version 5.0; GraphPad Software, San Diego, CA, USA). Differences with values of ${ }^{*} p<0.05,{ }^{* *} p<0.01$, and $* * 0<0.001$ were considered statistically significant.

\section{Abbreviations}

Mtb: Mycobacterium tuberculosis; TB: Tuberculosis; ROS: Reactive oxygen species; LCN2: Lipocalin 2; PLC: Peptide loading complex; MHC: Major histocompatibility complex; ERAP: Endoplasmic reticulum aminopeptidase; PDI: Protein disulfide isomerase; CRT: Calreticulin; MOI: Multiplicity of infection; CFU: Colony-forming units; GM-CSF: Granulocyte-macrophage colony-stimulating factor; M-CSF: Macrophage colony-stimulating factor; NAC: N-acetyl cysteine; DPI: Diphenyleneiodonium; BMDCs: Bone marrow derived-dendritic cells; BMDMs: Bone marrow derived-macrophages; TNF: Tumor necrosis factor; IL: Interleukin; IFN: Interferon; LPS: Lipopolysaccharide; LN: Lymph node; WT: Wild-type; ER: Endoplasmic reticulum; PBS: Phosphate-buffered saline; PFA: Paraformaldehyde; APC: Allophycocyanin; PE: Phycoerythrin; mAbs: Monoclonal antibodies; MCP: Monocyte chemoattractant protein.

\section{Supplementary Information}

The online version contains supplementary material available at https://doi. org/10.1186/s13578-021-00686-2.

Additional file 1: Figure S1. LCN2 is induced following Mtb infection in BMDCs. Figure S2. LCN2 induced ROS-related molecules in Mtb-infected BMDCs. Figure S3. Effects of LCN2-mediated ROS on formation of the PLC in BMDCs. Figure S4. LCN2 regulates MHC class I molecule expression and $\mathrm{CD}^{+}{ }^{+}$effector T-cell generation following intravenous Mtb infection. Figure S5. LCN2 does not affect the total T-cell population following Mtb infection. Figure S6. LCN2 in BMDCs is important to regulate CD8 ${ }^{+}$effector T-cell generation following Mtb infection. Figure S7. Mtb-induced effector $\mathrm{CD}^{+} \mathrm{T}$ cells regulate intracellular Mtb. Figure S8. LCN2 induced ROS-related molecules in Mtb-infected BMDCs. Figure S9. LCN2 regulates intracellular Mtb survival.

\section{Acknowledgements}

Not applicable.

\section{Authors' contributions}

JAC designed the study, performed the majority of the experiments, analyzed the data and wrote the manuscript; JL, SNC, SHS, TDN, and SAL analyzed data and provided expert technical assistance; CHS designed the study, supervised the project and wrote the manuscript. All authors read and approved the final manuscript.

\section{Funding}

This work was supported by the National Research Foundation of Korea (NRF) grant funded by the Korea government (MSIT) (2020R1A2C2005605). The funders had no role in study design, data collection and analysis decision to publish, or preparation of the manuscript.

\section{Availability of data and materials}

The datasets supporting the conclusions of this article are included within the article and its additional files.

\section{Declarations}

\section{Ethics approval and consent to participate}

All animal procedures were reviewed and approved by the Institutional Animal Care and Use Committee of Chungnam National University (permit no. CNU-00907). Animal experiments were performed in accordance with Korean Food and Drug Administration guidelines.

\section{Consent for publication}

All authors agree to publish this paper.

\section{Competing interests}

No competing interests declared.

\section{Author details}

${ }^{1}$ Department of Microbiology, Department of Medical Science, College of Medicine, Chungnam National University, 266 Munhwa-ro, Jung-gu, 
35015 Daejeon, South Korea. ${ }^{2}$ Department of Medical Science, College of Medicine, Chungnam National University, 266 Munhwa-ro, Jung-gu, Daejeon 35015, South Korea. ${ }^{3}$ Translational Immunology Institute, Chungnam National University, 99 Daehak-ro, Yuseong-gu, 34134 Daejeon, South Korea.

Received: 24 March 2021 Accepted: 1 September 2021 Published online: 25 September 2021

\section{References}

1. World Health Organisation. Global tuberculosis report 2017. Geneva: EHO; 2017.

2. Paul BT, Manz DH, Torti FM, Torti V. Mitochondria and Iron: current questions. Expert Rev Hematol. 2017;10:65-79.

3. Skaar EP. The battle for iron between bacterial pathogens and their vertebrate hosts. PLoS Pathog. 2010;6:e1000949.

4. Wilson BR, Bogdan AR, Miyazawa M, Hashimoto K, Tsuji Y. Siderophores in Iron metabolism: from mechanism to therapy potential. Trends Mol Med. 2016;22:1077-90.

5. Rook GA, Steele J, Ainsworth M, Champion BR. Activation of macrophages to inhibit proliferation of Mycobacterium tuberculosis: comparison of the effects of recombinant gamma-interferon on human monocytes and murine peritoneal macrophages. Immunology. 1986;59:333-8.

6. De Voss JJ, Rutter K, Schroeder BG, Su H, Zhu Y, Barry CE. The salicylatederived mycobactin siderophores of Mycobacterium tuberculosis are essential for growth in macrophages. Proc Natl Acad Sci U S A. 2000:97:1252-7.

7. Lounis N, Truffot-Pernot C, Grosset J, Gordeuk VR, Boelaert JR. Iron and Mycobacterium tuberculosis infection. J Clin Virol. 2001;20:123-6.

8. Asimakopoulou A, Weiskirchen S, Weiskirchen R. Lipocalin 2 (LCN2) expression in hepatic malfunction and therapy. Front Physiol. 2016;7:430.

9. Abergel RJ, Wilson MK, Arceneaux JE, Hoette TM, Strong RK, Byers BR, Raymond KN. Anthrax pathogen evades the mammalian immune system through stealth siderophore production. Proc Natl Acad Sci U S A. 2006;103:18499-503.

10. Holmes MA, Paulsene W, Jide X, Ratledge C, Strong RK. Siderocalin (Lcn 2) also binds carboxymycobactins, potentially defending against mycobacterial infections through iron sequestration. Structure. 2005;13:29-41.

11. Bachman MA, Lenio S, Schmidt L, Oyler JE, Weiser JN. Interaction of lipocalin 2, transferrin, and siderophores determines the replicative niche of Klebsiella pneumoniae during pneumonia. MBio. 2012;3:e00224-11.

12. Johnson EE, Srikanth CV, Sandgren A, Harrington L, Trebicka E, Wang L, Borregaard N, Murray M, Cherayil BJ. Siderocalin inhibits the intracellular replication of Mycobacterium tuberculosis in macrophages. FEMS Immunol Med Microbiol. 2010;58:138-45.

13. Saiga H, Nishimura J, Kuwata H, Okuyama M, Matsumoto S, Sato S, Matsumoto M, Akira S, Yoshikai Y, Honda K, Yamamoto M, Takeda K. Lipocalin 2-dependent inhibition of mycobacterial growth in alveolar epithelium. J Immunol. 2008;181:8521-7.

14. Guglani L, Gopal R, Rangel-Moreno J, Junecko BF, Lin Y, Berger T, Mak TW, Alcorn JF, Randall TD, Reinhart TA, Chan YR, Khader SA. Lipocalin 2 regulates inflammation during pulmonary mycobacterial infections. PLoS ONE. 2012;7:e50052.

15. Liu Z, Petersen R, Devireddy L. Impaired neutrophil function in $24 p 3$ null mice contributes to enhanced susceptibility to bacterial infections. J Immunol. 2013;190:4692-706.

16. Myrvik QN, Leake ES, Wright MJ. Disruption of phagosomal membranes of normal alveolar macrophages by the H37Rv strain of Mycobacterium tuberculosis. A correlate of virulence. Am Rev Respir Dis. 1984;129:322-8.

17. Sousa AO, Mazzaccaro RJ, Russell RG, Lee FK, Turner OC, Hong S, Van Kaer L, Bloom BR. Relative contributions of distinct MHC class I-dependent cell populations in protection to tuberculosis infection in mice. Proc Natl Acad Sci U S A. 2000;97:4204-8.

18. Behar SM, Dascher CC, Grusby MJ, Wang CR, Brenner MB. Susceptibility of mice deficient in CD1D or TAP1 to infection with Mycobacterium tuberculosis. J Exp Med. 1999;189:1973-80.

19. Elliott T, Williams A. The optimization of peptide cargo bound to MHC class I molecules by the peptide-loading complex. Immunol Rev. 2005;207:89-99.
20. Park B, Lee S, Kim E, Cho K, Riddell SR, Cho S, Ahn K. Redox regulation facilitates optimal peptide selection by MHC class during antigen processing. Cell. 2006;127:369-82.

21. Blanchard N, Kanaseki T, Escobar H, Delebecque F, Nagarajan NA, ReyesVargas E, Crockett DK, Raulet DH, Delgado JC, Shastri N. Endoplasmic reticulum aminopeptidase associated with antigen processing defines the composition and structure of MHC class I peptide repertoire in normal and virus-infected cells. J Immunol. 2010;184:3033-42.

22. Serwold T, Gonzalez F, Kim J, Jacob R, Shastri N. ERAAP customizes peptides for MHC class I molecules in the endoplasmic reticulum. Nature. 2002;419:480-3.

23. Mayer-Barber KD, Barber DL. Innate and adaptive cellular immune responses to Mycobacterium tuberculosis infection. Cold Spring Harb Perspect Med. 2015;5:18424.

24. Prezzemolo T, Guggino G, La Manna MP, Di Liberto D, Dieli F, Caccamo N. Functional signatures of human CD4 and CD8 T cell responses to Mycobacterium tuberculosis. Front Immunol. 2014;5:180.

25. Piloni NE, Fermandez V, Videla LA, Puntarulo. S., Acute iron overload and oxidative stress in brain. Toxicology. 2013;314:174-82.

26. Wang G, Liu S, Wang L, Meng L, Cui C, Zhang H, Hu S, Ma N, Wei Y. Lipocalin-2 promotes endoplasmic reticulum stress and proliferation by augmenting intracellular iron in human pulmonary arterial smooth muscle cells. Int J Biol Sci. 2017;13:135-44.

27. Domingo-Gonzalez R, Prince O, Cooper A, Khader SA. Cytokines and chemokines in Mycobacterium tuberculosis infection. Microbiol Spectr. 2016:4:4-5.

28. Flo TH, Smith KD, Sato S, Rodriguez DJ, Holmes MA, Strong RK, Akira S, Aderem A. Lipocalin 2 mediates an innate immune response to bacterial infection by sequestrating iron. Nature. 2004;432:917-21.

29. Nairz M, Schroll A, Haschka D, Dichtl S, Sonnweber T, Theurl I, Theurl M, Lindner E, Demetz E, Asshoff M, Bellmann-Weiler R, Muller R, Gerner RR, Moschen AR, Baumgartner N, Moser PL, Talasz H, Tilg H, Fang FC, Weiss G. Lipocalin-2 ensures host defense against Salmonella Typhimurium by controlling macrophage iron homeostasis and immune response. Eur J Immunol. 2015:45:3073-86.

30. Papanikolaou G, Pantopoulos K. Iron metabolism and toxicity. Toxicol Appl Pharmacol. 2005;202:199-211.

31. Sottile R, Federico G, Garofalo C, Tallerico R, Faniello MC, Quaresima B, Cristiani CM, Sanzo D, Cuda M, Ventura G, Wagner V, Contro AK, Perrotti G, Gulletta N, Ferrone E, Karre S, Costanzo K, Carlomagno FS, Carbone E. Iron and ferritin modulate MHC class I expression and NK cell recognition. Front Immunol. 2019;10:224.

32. Tector M, Salter RD. Calnexin influences folding of human class I histocompatibility proteins but not their assembly with beta 2-microglobulin. J Biol Chem. 1995;270:19638-42.

33. Hetz C. The unfolded protein response: controlling cell fate decisions under ER stress and beyond. Nat Rev Mol Cell Biol. 2012;13:89-102.

34. Thomaidou S, Kracht MJL, van der Slik A, Laban S, de Koning EJ, Carlotti F, Hoeben RC, Roep BO, Zaldumbide A. Beta-cell stress shapes CTL immune recognition of preproinsulin signal peptide by posttranscriptional regulation of endoplasmic reticulum aminopeptidase 1. Diabetes. 2020;69:670-80.

35. Dahl SL, Woodworth JS, Lerche CJ, Cramer EP, Nielsen PR, Moser C, Thomsen AR, Borregaard N, Cowland JB. Lipocalin-2 functions as inhibitor of innate resistance to Mycobacterium tuberculosis. Front Immunol. 2018;9:2717.

36. Denis M. Tumor necrosis factor and granulocyte macrophage-colony stimulating factor stimulate human macrophages to restrict growth of virulent Mycobacterium avium and to kill avirulent M. avium: killing effector mechanism depends on the generation of reactive nitrogen intermediates. J Leukoc Biol. 1991;49:380-7.

37. Havell EA. Evidence that tumor necrosis factor has an important role in antibacterial resistance. J Immunol. 1989;143:2894-9.

38. Keane J, Balcewicz-Sablinska MK, Remold HG, Chupp GL, Meek BB, Fenton $\mathrm{MJ}$, Kornfeld H. Infection by Mycobacterium tuberculosis promotes human alveolar macrophage apoptosis. Infect Immun. 1997;65:298-304.

39. Bean AG, Roach DR, Briscoe H, France MP, Korner H, Sedgwick JD, Britton WJ. Structural deficiencies in granuloma formation in TNF gene-targeted 
mice underlie the heightened susceptibility to aerosol Mycobacterium tuberculosis infection, which is not compensated for by lymphotoxin. J Immunol. 1999;162:3504-11.

40. Martinez AN, Mehra S, Kaushal D. Role of interleukin 6 in innate immunity to Mycobacterium tuberculosis infection. J Infect Dis. 2013;207:1253-61.

41. Gira AK, Kowalczyk AP, Feng Y, Swerlick RA. Iron chelators and hypoxia mimetics inhibit IFNgamma-mediated Jak-STAT signaling. J Invest Dermatol. 2009;129:723-9.

42. Cheng L, Xing H, Mao X, Li L, Li X, Li Q. Lipocalin-2 promotes m1 macrophages polarization in a mouse cardiac ischaemia-reperfusion injury model. Scand J Immunol. 2015;81:31-8.

43. Toyonaga T, Matsuura M, Mori K, Honzawa Y, Minami N, Yamada S, Kobayashi T, Hibi T, Nakase H. Lipocalin 2 prevents intestinal inflammation by enhancing phagocytic bacterial clearance in macrophages. Sci Rep. 2016;6:35014.

44. Lim YJ, Yi MH, Choi JA, Lee J, Han JY, Jo SH, Oh SM, Cho HJ, Kim DW, Kang $\mathrm{MW}$, Song $\mathrm{CH}$. Roles of endoplasmic reticulum stress-mediated apoptosis in M1-polarized macrophages during mycobacterial infections. Sci Rep. 2016;6:37211
45. Jung ID, Lee MG, Chang JH, Lee JS, Jeong YI, Lee CM, Park WS, Han J, Seo SK, Lee SY, Park YM. Blockade of indoleamine 2,3-dioxygenase protects mice against lipopolysaccharide-induced endotoxin shock. J Immunol. 2009;182:3146-54.

46. Choi JA, Lim YJ, Cho SN, Lee JH, Jeong JA, Kim EJ, Park JB, Kim SH, Park HS, $\mathrm{Kim} \mathrm{HJ}$, Song CH. Mycobacterial HBHA induces endoplasmic reticulum stress-mediated apoptosis through the generation of reactive oxygen species and cytosolic Ca2 + in murine macrophage RAW 264.7 cells. Cell Death Dis. 2013;4:e957.

\section{Publisher's Note}

Springer Nature remains neutral with regard to jurisdictional claims in published maps and institutional affiliations.
Ready to submit your research? Choose BMC and benefit from:

- fast, convenient online submission

- thorough peer review by experienced researchers in your field

- rapid publication on acceptance

- support for research data, including large and complex data types

- gold Open Access which fosters wider collaboration and increased citations

- maximum visibility for your research: over $100 \mathrm{M}$ website views per year

At BMC, research is always in progress.

Learn more biomedcentral.com/submissions 